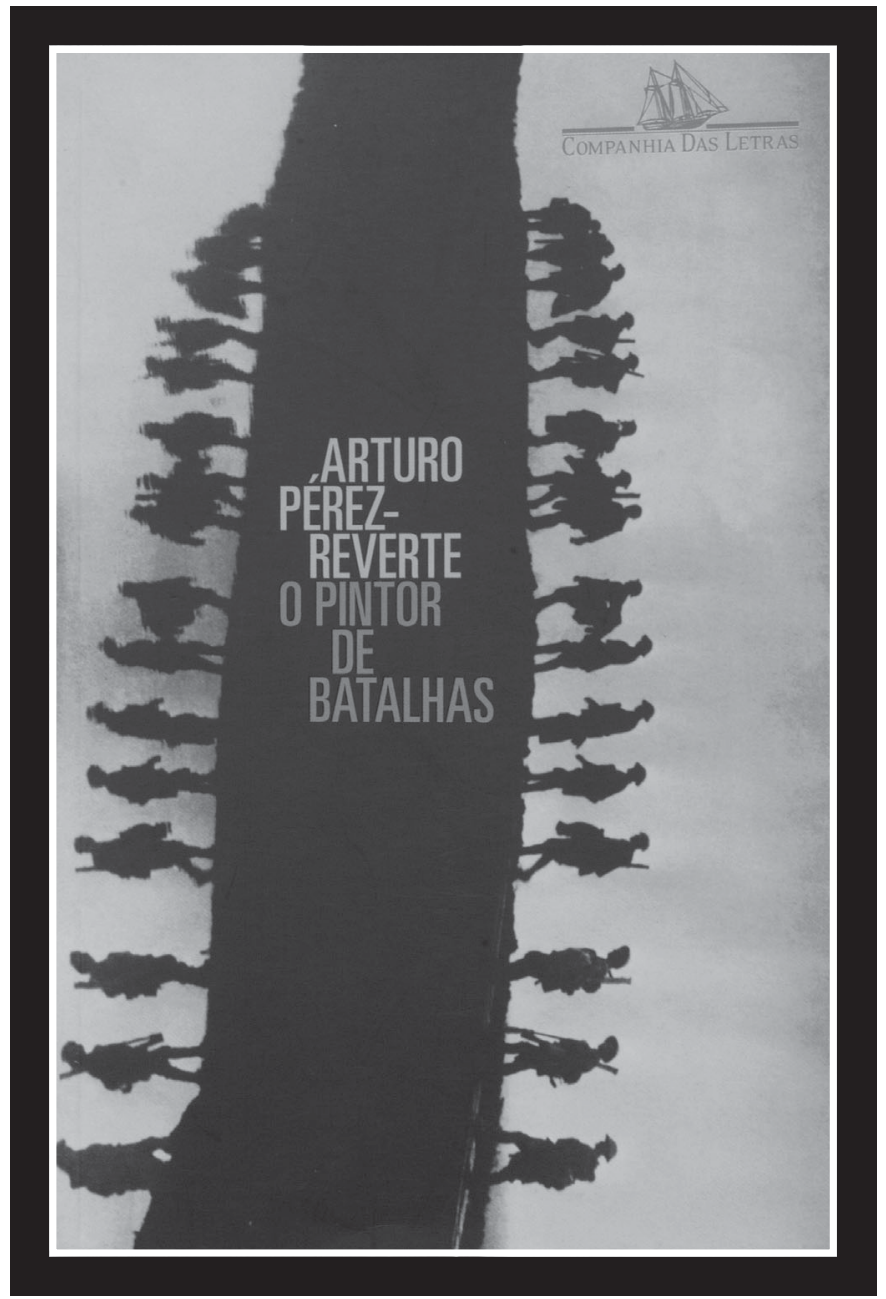

O pintor de batalhas, de Arturo Pérez-Reverte. São Paulo: Companhia da Letras, 2008, 250 páginas. 


\section{A imagem como tragédia}

Fernando de Tacca*

Robert Capa tornou-se um grande mito da fotografia de guerra ao estar sempre muito próximo dos acontecimentos, como um possível alvo. Como ele mesmo dizia, não sendo assim, não faria uma boa fotografia dos acontecimentos trágicos dos conflitos. Foi traído por um inimigo invisível: pisou em uma mina terrestre e morreu na Guerra da Indochina.

O fotógrafo de guerra parece sempre um elemento dotado de uma liberdade extrema, colocando sua vida em risco por imagens chocantes ou que evocam os piores lados da humanidade, quando qualquer razão cede para valores fluidos de nacionalismos acerbados ou de ideologias autoritárias, nas quais o indivíduo perde qualquer noção de juízo. Estando estes fotógrafos perto de tantas atrocidades, perguntamo-nos como conseguem suportar tais situações e como conseguem sobreviver. Sabemos que sempre fotografam, exercendo e concluindo sua função com o ato fotográfico, mesmo em situações nas quais talvez queiramos que tenham feito alguma interferência além do click, para salvar ou tentar salvar alguém.

Kevin Carter, fotógrafo sul-africano do chamado Clube do Bang-Bang, esteve com seus companheiros sempre muito perto da morte, a sua ou a dos que fotografava. Sua tragédia pessoal foi associada a uma fotografia que ganhou o Prêmio Pulitzer, em 1994. A pequena garota africana, nua, sentada no chão, sendo observada por um abutre, leva o leitor, imagética e simbolicamente, a uma idéia de fome animal, de espera da carniça humana, sendo seu autor sempre cobrado de um posicionamento: o que você fez para salvar a pobre criança? Mesmo explicando que a situação traduz uma realidade

\footnotetext{
* Fernando de Tacca é fotógrafo, professor livre docente na Unicamp e editor da revista Studium. É autor do livro Imagens do sagrado: entre a Paris Match e O Cruzeiro (Editora da Unicamp) com lançamento em 2009.
} 
simbólica e não necessariamente efetiva, que a imagem conduz para uma significação além do contexto, que o abutre não estava esperando a morte da garota, a questão sempre lhe era apresentada. Assim, seu suicídio carrega simbolicamente o trauma da foto.

No filme macedônio Antes da chuva (1994, Milcho Manchevski), um experiente fotógrafo de guerra (Aleksander Kirkov), também vencedor do Prêmio Pulitzer, entra em crise existencial pela imagem contemplada no concurso. Ele se sente participante da morte de uma pessoa ao fotografar seu momento final, e menos por não ter tentado interferir. Por participar fotografando, como sujeito ativo, ele se culpa, já que a ação do disparo foi realizada para resultar em imagem, e ele foi um dos operadores da tragédia. Esta situação já havia sido amplamente divulgada pela imprensa com a conhecida fotografia de Eddie Adams, na qual o chefe de polícia sul-vietnamita Nguyen Ngoc Loan executa um civil suspeito de ser um guerrilheiro vietcong, e o faz para as câmeras dos fotógrafos e cineastas.

A crise de Aleksander Kirkov o leva de volta às suas origens em uma pequena aldeia na Macedônia, na fronteira com a Albânia, onde ocorre um conflito étnico nacionalista, e o leva à morte. A fotografia de um jovem bósnio sendo executado por um sérvio, simplesmente porque ouviu o fotógrafo dizer que não havia realizado uma boa fotografia naquele dia, o fez matar para ter a imagem.

Ainda no campo do cinema, uma fotógrafa representada por Mira Sorvino no filme Desejos de liberdade (2002, Edoardo Ponti) não consegue se lembrar do que aconteceu com uma garota fotografada durante a guerra da Angola. A fotografía é publicada na capa da revista Time, o que lhe é muito prestigioso. Entretanto, a simples questão de uma angolana, sobre o que aconteceu com a garota, faz a fotógrafa sair em busca de respostas em seus arquivos. Entretanto, ela não consegue encontrar informações sobre o destino da criança, se sobreviveu ou não, e também entra em crise existencial, tentando uma redenção ao final do filme, em trabalhos humanitários, pois a fotografia já não era lugar da vida, mas da morte. 
Todo esse preâmbulo nos remete ao livro de Arturo Perez-Reverte, romancista espanhol muito reconhecido e premiado. Em seu livro El pintor de batallas ${ }^{2}$, essas questões voltam com intensidades próprias da literatura. Perez-Reverte é jornalista, membro da Real Academia Espanhola, foi correspondente de guerra em vários conflitos, inclusive nos Bálcãs, pelo qual recebeu o Premio Asturias de Jornalismo. El pintor de batallas teve grande repercussão ao receber dois prêmios em 2008: Premio Vallombrosa Gregor von Rezzori e Grand Prix Littéraire SaintEmilion Pomerol Fronsac.

André Faulques, um fotógrafo conhecido de conflitos e guerra, ganhador também do Prêmio Pulitzer, retira-se para um lugar isolado no Mediterrâneo, onde tenta produzir um grande mural de uma cena épica, na qual todas as guerras estariam representadas, e todas as imagens que não conseguiu fotografar estariam presentes. Entretanto, sua fuga rumo ao épico e ao isolamento permite um encontro com sua criação. $\mathrm{O}$ bósnio Ivo Markovic, fotografado na imagem vencedora do Prêmio Pulitzer, consegue chegar ao "esconderijo" de Faulques, depois de anos à sua procura.

A morte fotográfica, ou o tempo estagnado na imagem, ganha nova dimensão quando a criatura encontra seu criador. Estabelece-se uma tensão constante, na qual Ivo Markovic torna-se uma espécie de exigência externa de uma formação de consciência moral do ato fotográfico, como superego para o fotógrafo. Nas cenas finais, quando manuseia o livro de André Faulques, encontra duas fotografias realizadas na África, com dois tempos distintos: a primeira, do choque de uma morte por machadadas; a segunda, com o corpo ensanguentado no chão. O fotógrafo se ajoelhou e pediu para não haver a execução, mas não foi convincente, como ele afirma. Entretanto, mesmo assim, fotografa a siuação, afinal o gesto técnico incorporado no fazer fotográfico é condicionante de um estado alterado de consciência, no qual sempre o fotógrafo mergulha profundamente.

\footnotetext{
${ }^{2}$ Fernando de Tacca resenhou o livro original, em espanhol (El pintor de batallas. Buenos Aires: Editora Afaguara, 2006), mas a versão em português já está disponível.
} 
El pintor de batallhas traz passagens para deleite dos aficionados pela fotografia e pelo mundo das imagens, como a comparação que faz do trabalho do fotógrafo e do franco-atirador, como dois elementos que compartilham escolhas e partem de um mesmo ponto de vista aportado pela tecnologia.

André Faulques tem uma estranha relação de amor: uma fotógrafa (Olvido) que está junto dele em muitas situações. É uma relação que acontece no companheirismo da profissão e nos momentos tensos do conflito. Entretanto, sendo muito mais crítica do que ele, ela somente fotografa detalhes; sem a presença humana, registra somente os resíduos da guerra, as suas ruínas recentes. É dela a crítica ao fotográfico, quando muitas vezes encontra no artista o lugar da verdade, pois afirma que "Sólo el artista es veraz. Es la fotografia la que miente". Seu fim é trágico e acontece ao fotografar um detalhe da guerra, ao se aproximar de um caderno escolar no chão com folhas arrancadas pelas explosões. Como Robert Capa, um inimigo invisível estava a sua espera escondido na relva. Ao pensar nela e em suas recordações do momento de sua morte, André Faulques repensa sua relação com a fotografia: "No era posible fotografiar el peligro, o la culpa. El sonido de una bala al reventar un cráneo. La risa de un hombre que acaba de ganar siete cigarrillas apostando sobre si el feto de la mujer a la qua ha desventrado con su bayoneta es varón o hembra. En cuanto al cadáver del servio descalzo, tal vez el escritor pudiera encontrar algunas palabras".

Quando a fotografia torna-se limitadora da imagem, o personagem principal, o fotógrafo transformado em pintor, busca na história da arte, em Brueghel, Goya, Ucello, suas referências para a concepção do grande mural épico de todas as guerras, algumas vezes citando fotografias clássicas, como a jovem de cabeça raspada na cidade de Chartres, na França, em1944.

O livro nos remete para um plano da tensão entre imagens, para um dialogismo imagético possível, e para um estado de tensão muito comum na literatura, quando a criatura encontra o criador e o coloca em um não-lugar. Entretanto, sua pintura tem término quando ele integra 
e cola em um espaço vazio do mural a famosa imagem de Markovic publicada na capa de uma revista, como única imagem fotográfica que continha verdade para ele. Afinal, Markovic estava por ali, espreitandoo em algum ponto da mata, como uma criatura insaciável de vingança, como uma consciência moral inatingível para Faulques, esperando ardilosamente para a redenção de sua imagem transformada em tragédia. Não foi preciso: a imagem como tragédia lhe foi apresentada na história pessoal do pintor de batalhas, na última fotografia que André Faulques fez de sua amada, em um gesto mortuário condicionado do ato fotográfico. 